\title{
Sebastián Salazar Bondy: alabanza y crítica del tradicionalismo limeño
}

\author{
Mario Granda \\ Universidad Antonio Ruiz de Montoya \\ mario.granda@uarm.pe
}

\section{Resumen}

Estudia la producción intelectual previa de Salazar Bondy, sus artículos publicados entre los años 1950-1964 donde fue gestando los temas que más tarde se convirtieron en una de las críticas más duras al tradicionalismo limeñista del siglo XX con el ensayo Lima la horrible (1964), donde realiza un escrupuloso análisis de las costumbres, la literatura, la pintura y otras expresiones artísticas y sociales limeñas que considera parte de este tradicionalismo y, en consecuencia, proyectan una imagen conservadora y pasadista sobre la ciudad y la sociedad. El estudio permite conocer cuáles fueron las ideas y presupuestos sobre los que partió para escribir su conocido ensayo.

Palabras clave: Sebastián Salazar Bondy, Tradición, Tradicionalismo, Crítica, Lima, Ideología, Lima la horrible

\begin{abstract}
He studies the previous intellectual production of Salazar Bondy, his articles published between the years 1950-1964 where he was gestating the topics that later became one of the hardest criticisms of the Limeñista traditionalism of the twentieth century with the essay Lima the horrible (1964), where he performs a scrupulous analysis of the customs, literature, painting and other artistic and social Lima that he considers part of this traditionalism and, consequently, they project a conservative and pasadista image about the city and society. The study allows us to know what were the ideas and budgets on which he left to write his well-known essay.
\end{abstract}

Keywords: Sebastián Salazar Bondy, Tradition, Traditionalism, Critique, Lima, Ideology, Lima la horrible 


\section{Sebastián Salazar Bondy: alabanza y crítica del tradicionalismo limeño}

\section{Introducción}

Hacia la década de 1950, la coyuntura política y económica mundial —marcada por la Guerra de Corea y la reconstrucción de Europa- colaboró significativamente con el crecimiento de las exportaciones, la inversión extranjera y el mejoramiento de la salud y educación pública del Perú (Contreras y Cueto 2004, pp. 297-299). Fue durante el gobierno del general Manuel Odría (1948-1956) que se en Lima construyeron los edificios del Mercado Central, el Ministerio de Educación y el Hospital del Empleado Edgardo Rebagliati, además de otras grandes obras para la industrialización de las regiones. La vida cotidiana de la capital también se vio muy favorecida, ya que se construyeron nuevas avenidas, creció el número de vehículos, se mejoró el transporte público y en las casas ya no solo había radios sino también televisores que permitían a las familias limeñas estar en contacto directo con noticias, imágenes e ideas de otras ciudades de la ciudad y del mundo. Aunque la vida en el campo aún conservaba las dinámicas de la economía latifundista, la vida urbana se caracterizará por su rápida modernización y su continuo contacto con la cultura de masas del mundo contemporáneo.

En este contexto social y cultural se encuentra situada la obra literaria y periodística más importante de Sebastián Salazar Bondy (1924-1965). Interesado por la poesía, la dramaturgia, la crítica literaria y la crítica de arte desde muy joven, su obra demuestra un vivo interés por explorar los diferentes elementos que componen la compleja realidad social, cultural y artística de la sociedad limeña, así como por cuestionar todo tipo de orden o prejuicio que impidiera consolidar una sociedad más democrática y solidaria. No es extraño descubrir que sea él uno de los primeros escritores de su tiempo en constatar que en la capital peruana aún prevalecían las diferencias de clases y ciertos grupos sociales gozaban de muchos privilegios frente a la gran mayoría. Por más que se estuvieran construyendo grandes edificios y se 
modernizara el transporte, los servicios sociales y hasta la educación, la capital peruana aún mantenía una estructura social conservadora y profundamente desigual. Las riquezas se encontraban bajo el poder de la oligarquía limeña (Cotler 1978), las tierras de cultivo pertenecían a los pocos miembros de la Sociedad Nacional Agraria y muchas minas estaban en manos de empresas extranjeras. La ansiada reforma agraria, prometida por sucesivos gobiernos, nunca llegaría a hacerse realidad, y las diferencias socioeconómicas entre las familias adineradas y la clase media se redujeron muy poco.

Otro elemento que refleja la estructura conservadora de la época es la vigencia del tradicionalismo limeñista. Bajo la retórica ya implantada de aquella «Lima que se va», algunos de los escritores de la generación del Centenario seguían insistiendo en la representación antañona de la ciudad y la mirada nostálgica del pasado. En 1953 se realizó un ciclo de conferencias titulado «Lima irreparable», donde Luis Alayza y Paz Soldán, José Gálvez y Raúl Porras Barrenechea recordaron la historia colonial y lamentaron los recientes cambios ocurridos en la capital. La charla de Porras, titulada «El río, el puente y la alameda» (que aparece en una edición de la Pequeña antología de Lima publicada en el año 1965) tiene interesantes reflexiones sobre la identidad cultural limeña y propone una mirada amplia y diversa sobre la tradición cultural de la capital. Sin embargo, no dejan de haber momentos en los que su prosa vuelve a remitirse al mito pasatista limeño. El río Rímac es el «obrero silencioso en la fecundación de la tierra y creador oculto de la fuerza motriz» (1965, p. 365) y la huerta de Pizarro (ya desaparecida en el momento en que escribe) es «un recuerdo sugestivo» que los limeños deben intentar no olvidar (Porras 1965, p. 378). Y como es de esperarse, Porras no deja de ocultar su desagrado con la arquitectura moderna, pues dice que no se ajusta al «espíritu» de la ciudad. El edificio de vidrio de estilo norteamericano, por ejemplo, está reñido con el concepto de la vida familiar, de ese hortus clausum colonial resguardado por celosías y ventanas. Es tiempo de volver a la vivienda «[...] clara, amplia, silenciosa, con el olor y el aire de nuestro propio paisaje y de nuestras necesidades morales [...]» (Porras 1965: 396).

Como se sabe, Salazar Bondy fue el autor de una de las críticas más duras al tradicionalismo limeñista del siglo XX. En su ensayo Lima la horrible (1964), realiza un escrupuloso análisis de las costumbres, la literatura, la pintura y otras expresiones artísticas y sociales limeñas que considera parte de este tradicionalismo $y$, en consecuencia, proyectan una imagen conservadora y pasatista sobre la ciudad y la sociedad. Sin embargo, nuestro interés no se encuentra en este libro sino en aquellos artículos publicados en los años anteriores - específicamente, entre los años de 1950 y 1964-, donde el escritor empezó a escribir sobre estos temas por primera vez. Por medio de este recorrido será posible conocer un poco más cuáles fueron las ideas y presupuestos sobre los que Salazar partió para escribir su conocido ensayo. 


\section{Tradición y tradicionalismo}

Para poder conocer la naturaleza del tradicionalismo limeño al que aquí hemos hecho referencia antes es necesario determinar qué semejanzas y qué diferencias existen entre los conceptos de «tradición» y «tradicionalismo». Según Karen Sanders, la tradición es el conjunto de conocimientos, referentes culturales y prácticas que tienen como función articular el pasado con el presente de una comunidad o grupo social:

Las tradiciones representan la ordenación de la materia bruta del pasado: se recuerdan algunas cosas y otras se olvidan a propósito, pero todo está estructurado de tal manera que el pasado viene a tener significado para que — también - el futuro pueda tener sentido. (Sanders 1997, pp. 83-84)

La identidad de un país o una clase social es producto de la manera en que un pasado es narrado, sea para la misma comunidad como para los que no pertenecen a esta comunidad y desean saber cómo es ella. Este pasado está fundamentado en personas, libros, relatos orales, instituciones, ceremonias y diversos tipos de acontecimientos que se revelan, ocultan, mantienen o suprimen según el modo narrativo en que se cuentan (Sanders 1997, p. 84). Así, la tradición es la base fundamental sobre la que una sociedad vive y preserva su cultura para las generaciones futuras. Si ella no se practica y transmite, cae en el olvido y desaparece porque ya no servirá para integrar y definir a la comunidad. La tradición, por tanto, debe ser dinámica y activa, pues se encarga de comunicar y afianzar en el presente y luego en el futuro los conocimientos y prácticas que distinguen y definen a una cultura.

Por su parte, el tradicionalismo también se interesa por preservar los conocimientos y las costumbres del pasado para que sean recordados por los hombres y mujeres del presente y las generaciones venideras. Pero a diferencia de la tradición, es intolerante a la transformación de las formas que sirven para recordar el pasado. El tradicionalismo se obstina en hacer una rígida selección de lo que se debe o no se debe recuperar en el presente, esforzándose lo más posible para que estas formas que recuerdan el pasado se mantengan iguales el periodo de tiempo más largo posible. No es extraño, por tanto, que se resista a los cambios y a la crítica. Así, mientras que la tradición tiende a tener una mirada abierta, dialéctica e integradora sobre la realidad y sobre sí misma (o sea, sobre el modo en que se recuerda el pasado para el presente y el futuro), el tradicionalismo más bien tiene una mirada cerrada y discriminante, pues lo que hace es jerarquizar ciertas formas de tradición sobre otras, visibilizando algunas e invisibilizando otras. Su interés está en determinar cuáles son los saberes oficiales y cuáles no y, a la larga, en crear situaciones de dominio en el campo de la realidad y en el campo de la representación de la realidad. 


\section{Admiración por la Colonia y redescubrimiento del Perú}

Casi siempre se ha dicho que Salazar Bondy fue un acérrimo enemigo de la Colonia (Velázquez 2002), pero esta idea puede cambiar si nos acercamos a los textos que empezó a publicar a comienzos de los años cincuenta. Esto lo descubrimos si nos acercamos a dos poemas publicados en el diario La Prensa y que, precisamente, tienen mucha afinidad con el tema colonial. Uno de ellos se titula «Desde el balcón» y el otro, «Plaza de Armas», incluye versos como estos:

Rostro del pueblo que calla y espera

Bajo la sombra de la crujiente catedral

Donde Pizarro puso su cadáver

Como la ardiente piedra de la fundación.

Plaza de Armas, niñez dorada y distante, amor primero y últimas miradas a la dicha (1950).

En la primera estrofa podemos observar que la Catedral y la figura del conquistador Francisco Pizarro se evocan como los ilustres símbolos de la tradición colonial y son vinculados al momento de la fundación de la ciudad de Lima. En la segunda, los dos versos recuerdan la Plaza de Armas desde los ojos de la infancia del propio poeta.

El entusiasmo por el tema colonial no solo será poético. Dos años después, en 1952, Salazar gana el Premio Nacional de dramaturgia con Rodil, una obra que recuerda la heroica defensa que realizó el mariscal español José Ramón Rodil de la Fortaleza de Real Felipe en el Callao, inspirada a su vez en una pieza de teatro de mismo nombre escrita por Ricardo Palma en el año 1851 (Salazar 1952). En el mes de enero del año 1953, por el aniversario de la capital, Salazar publica un artículo en el que se recuerda la llegada de los españoles al valle del Rímac y el acto de fundación de la ciudad. La breve narración describe a Francisco Pizarro divisando el paisaje que muy pronto albergará a la ciudad:

El hombre miraba desde una altura la tierra apenas verdecida, y distinguía a lo lejos el mar abrazado por las dos salientes de la bahía [...]. La ciudad ya estaba allí, en las imágenes que el vencedor animaba sobre la soledad de la pequeña campiña. (1953a)

Para Salazar, el momento de la fundación tiene mucha importancia porque refleja la voluntad de los hombres — en este caso, los conquistadores españoles- por dar inicio a una nueva civilización.

E1 tópico colonial se encuentra también en los artículos que escribirá sobre las Tradiciones Peruanas de Ricardo Palma. En el año 1953, por los ciento veinte años del nacimiento, Salazar afirma que la ciudad de Lima se encuentra en deuda con la memoria de Palma porque no se preocupa por incentivar 
el interés en su vida ni en su obra. De hecho, apenas existe una pequeña calle que recuerda su nombre: «Falta el monumento que perennice su obra y muestre nuestra gratitud para con su celo de literatura y su labor de bibliotecario» (1953e). Salazar también hace algunas afirmaciones sobre la obra literaria del escritor. Según él, las Tradiciones fueron «la realización de aquel museo del pasado nacional» en el que se funda «una mitología exclusiva del Perú» (1953b). En otro artículo publicado en el año 1958, Salazar no solo vuelve a recordar a Palma - pues ahora es el 125 aniversario de su nacimientosino a defenderlo de aquellos que lo acusan de ser un escritor "provincial» y carente de «la grandeza del gran poeta» (1958a). Por el contrario, no se debe olvidar - como ya lo dijera Porras - que Palma fue el segundo fundador de la ciudad, pues fue el que permitió a los limeños conocer y profundizar en su más honda realidad. Así como París no se puede imaginar sin Balzac y Río de Janeiro sin Machado de Assis, las letras peruanas carecerían de una marca decisiva si no es que no se contara con las Tradiciones. Por más que el rostro perricholesco de la ciudad moleste a algunos, «[...] es imposible ver a nuestra capital sin ese perfil cortesano que le dio Palma, y calles, plazas, monumentos, que ahora recorremos evocando las leyendas que él revivió o creó, perderán su encanto» (1958a).

Salazar aprecia especialmente la habilidad de Palma para revelar la vida cotidiana del virreinato, pues permite al lector ingresar a ese trasfondo humano que suele estar vedado a los investigadores de la historia: "Afortunadamente no fue historiador. Si lo hubiera sido, nos habría dejado solamente un buen texto de consulta". La habilidad del escritor se encuentra en haber tomado los documentos y testimonios del pasado como puntos de partida de una fantasía que logra develar "las verdades ocultas, las que no aparecen en los viejos papeles que maneja el historiador" (1958a). Gracias a que tomó el camino de la literatura y no el de la historia, sus Tradiciones logran revelar la «noción viva» del pasado. Poco más adelante, añade: «¿Qué importa si algo — poco o bastante - de lo que contó no fue cierto, si fue, como reza el proverbio italiano, "ben trovato"?» (1958a) A Salazar no le preocupa que la historia se recree con exactitud si es que la ficción colabora con la eficacia artística de los relatos.

La afinidad de Salazar con los temas y la literatura inspirada en la Colonia proviene en principio del prestigio que tenía el tradicionalismo en su tiempo. Nacido en el año 1924 y criado en una familia de clase media limeña, el escritor es hijo de esa época en que la literatura más celebrada era aquella vinculada con el prestigioso pasado de la capital - a sus once años, Lima celebraba con mucha pompa sus 400 años de fundación - o aquella que intentaba explorar un poco más el mundo criollo, como lo empezaron a hacer escritores como José Diez Canseco y Manuel Beingolea. No obstante, la mirada de Salazar hacia la Colonia no siempre será igual. Poco a poco y a partir de una serie de experiencias personales, nuevas lecturas 
y afinidades políticas, el escritor empezará a descubrir y finalmente a cuestionar el carácter ideológico de todo aquello que estuviera relacionado con ella.

Una experiencia que sirvió mucho para ampliar su perspectiva sobre la literatura y el teatro y redescubrir la relación afectiva e intelectual con su propio país fue la temporada que vivió en la ciudad de Buenos Aires entre 1947 y 1951. Además de conocer el círculo literario bonaerense, entrar en contacto con el teatro de vanguardia y colaborar en revistas tan importantes del momento como Sur, fue en esta ciudad donde, según confesión propia, Salazar descubrió el «Perú real» y no el Perú "de los himnos, de los símbolos" (2003, p. 41). Gracias al acceso a información estadística que tuvo la oportunidad de conocer, el escritor descubrió que el país de donde provenía era uno de los más hambrientos, semicolonizados y de mortalidad infantil más alta en América: en pocas palabras, «uno de los países más tristes del universo» (2003: 41). Salazar recordará en más de una ocasión este momento de su vida, pues le permitió ver su propio país, su país natal, desde una perspectiva nueva y realista:

A través de la nostalgia del país natal y de los míos, por un conducto sentimental, fui hallando, en el extranjero, la verdad. Un día, del cual no recuerdo la fecha pero sí la luz y el sonido, me di con una deslumbrada certeza. Mis lecturas de los días anteriores a esa jornada de descubrimiento no habían sido literarias. No leía, devoraba textos de cifras, datos estadísticos, de cuadros sinópticos aparentemente áridos. A través de dichos guarismos secos, irrebatibles por su sequedad, encontré los hechos patéticos que me revelaron mis deberes de escritor, de intelectual. (1960a)

Como puede observarse, esta nueva información que recibe le hace descubrir un país que estaba oculto a sus ojos mientras vivía en él. El cambio de lugar y la distancia tienen un efecto tanto en el ámbito intelectual como en el ámbito emocional del joven escritor.

A su regreso a Lima, Salazar retomará la vida literaria y dará inicio a una intensa vida periodística y cultural. En diferentes diarios y revistas limeños $-\mathrm{y}$ muchas veces usando diferentes pseudónimos para no acaparar tanto protagonismo a ojos de sus lectores-, el escritor utilizará sus columnas como una tribuna para tocar temas que siempre estaban relacionados con la literatura, el teatro, las artes plásticas, la música y la arquitectura. Para Salazar es necesario despertar en el ciudadano la inquietud crítica, pues la cultura no solo consiste en acumular conocimientos o visitar exposiciones de arte sino también en motivar el debate de las ideas y propiciar la reflexión sobre el modo en que cada creador - escritor, pintor o arquitecto- se relaciona con su tema. Así, su preocupación no está solo en informar sobre las obras teatrales del momento, las nuevas revistas literarias o la última exposición de un artista extranjero sino en reflexionar sobre cómo actividades como estas sirven para intercambiar ideas con el público, debatir sobre las corrientes literarias del momento o pensar en las maneras en que se puede ofrecer un mayor acceso a la cultura (Susti 2014a, p. 17). Para él, la visión crítica de un periodista debe ser más amplia y 
no limitarse a aquel tema en el que es especialista y es por ello que en sus columnas también encontramos comentarios sobre el urbanismo, los parques de la ciudad, la nueva música popular andina que se canta en los coliseos, las políticas culturales del Estado o hasta el maltrato a la comunidad de amueshas en la selva.

\section{La lectura de la obra crítica de José Carlos Mariátegui}

Otro momento importante en la historia del pensamiento de Salazar es el que corresponde a la lectura que hace de los ensayos de José Carlos Mariátegui a mediados de los años cincuenta. ${ }^{1} \mathrm{El}$ escritor admira el modo en que el Amauta se enfrentó tanto al tradicionalismo limeñista de su tiempo (Salazar 1954) como a la crítica literaria, que no ejercía su labor como era debido porque siempre era indulgente con las obras que comentaba (Calle 2016). Con su rechazo, Mariátegui no solamente buscaba una literatura que asuma el problema nacional de una manera más realista sino un cambio necesario en el orden social vigente (Mariátegui [1928] 1977).

Actitud parecida se puede encontrar en los ensayos de Sebastián Salazar Bondy a partir de este momento. Al igual que su mentor, el escritor también resaltará tanto la necesidad de terminar con esa literatura de evasión y juegos estéticos (la «mal llamada tradición») y hacer frente a ese tipo de crítica que siempre se muestra condescendiente. Tal como lo señala en una columna titulada "Los críticos del crítico", Salazar desconfía de esas alianzas e «influencias extrañas» que establece la crítica y que impiden un juicio honesto e imparcial. En vez de servir para señalar lo bueno sobre lo malo o lo pésimo, la crítica ha terminado por consentir cualquier tipo de expresión, convirtiendo las columnas de los diarios en «una suerte de decoración amable y cortesana» (1954c). En realidad, la función del crítico es sobre todo orientadora y pedagógica, pues debe ofrecer a los lectores los instrumentos necesarios para que aprecien el objeto artístico y enseñar dónde radica la falla y el acierto de la obra.

Pero además de promover una crítica comprometida y libre de consensos, Salazar también se encuentra en la búsqueda — como también hiciera Mariátegui- de una literatura realista más comprometida con el presente "que conmueve e inquieta" (1954a). En una columna dedicada a las características del arte contemporáneo, Salazar sostiene que el escritor y el artista «son testigos obligados a deponer sin disimulos sus acusadoras verificaciones» cuando se trata de hacer arte o literatura (1955b). La tarea de todo creador consiste en revelar las injusticias y la discriminación que se cometen día a día contra la sociedad, no en ocultarlas o ser indiferente a ellas. Sin embargo, esta obligación no es una negación de la vida del propio escritor

1 Un interesante aporte a la lectura de Mariátegui realizada por Salazar Bondy se encuentra en la conferencia ofrecida por Ricardo Portocarrero en el Coloquio Sebastián Salazar Bondy: Todo esto es mi país, organizado en el año 2015 por la Universidad de Lima (VV.AA. 2017). 
sino una afirmación vital. Tal como lo dice en una conferencia suya titulada «El deber del escritor en un país subdesarrollado», Salazar concluye que el propósito del realismo literario se funda en una «alegría futura, el bienestar colectivo, la dicha de poseer en común lo que se crea en común» (1960a). La literatura no solo es vista como un medio para revelar los problemas actuales, sobre los que el escritor debe prestar constante atención, sino también para buscar una sociedad mejor, una utopía.

Es precisamente en esta conferencia, presentada en un congreso de escritores en Chile, donde Salazar vuelve a citar el ensayo "El proceso de la literatura":

Suscribo, por ello, pese a que no participo, de su fundamento, marxista, una frase de José Carlos Mariátegui, con la cual concluyo estas palabras que son, a la postre, la confesión de una experiencia personal: «Mi voluntad es afirmativa, mi temperamento es de constructor y nada me es más antiético que el bohemio puramente iconoclasta y disolvente, pero mi misión ante el pasado (y ante el presente) parece ser la de votar en contra» (1960a).

Para Salazar, el compromiso con la realidad corresponde a la visión de una sociedad futura, ya que obedece a una voluntad afirmativa y constructiva. Este compromiso, además, no obedece a una actitud superficial ni a ciertas ideas pasajeras, como tampoco a un deseo destructivo y negativo sino más bien creador. Es significativa la pequeña variación en paréntesis que se agrega hacia el final de la cita. ${ }^{2}$ En vez de decir que el "voto en contra" solamente se dirige hacia el pasado, como hace Mariátegui, Salazar sugiere que este voto también debe estar dirigido "ante el presente". Así, su apuesta no solo responde ante la tradición heredada sino ante la realidad actual que le motiva a actuar.

La preferencia de Salazar por el realismo también se encuentra en su opinión sobre la historia de la pintura en el Perú. Según Salazar, es importante que el pintor pueda transmitir un mensaje que pueda ser entendido por el espectador (1954b), pero esto no es lo que ocurre con el arte colonial, que es la expresión de una represión: en vez de representar la contingencia de la vida cotidiana, la pintura de la Colonia fue siempre un arte "publicitario» que sirvió para difundir los valores de una nueva cultura y una nueva religión (1955c). En ella se representan a los cortesanos, los santos, los encajes áureos y las figuras celestiales, pero nunca la realidad histórica el país. Esta lejanía entre el Perú y la realidad se mantendrá aún en el siglo XIX. Ignacio Merino vivió durante una temporada en el país, pero eligió dedicarse a representar «la exterioridad falsamente universal y a la moda» (Salazar 1955c), mientras que Francisco Lazo realizó un tímido acercamiento hacia el Perú, pero casi toda su obra siguió los preceptos artísticos europeos. Sucederá lo mismo con

2 La oración original es: «Contra lo que baratamente pueda sospecharse, mi voluntad es afirmativa, mi temperamento es de constructor y nada me es más antiético que el bohemio puramente iconoclasta y disolvente; pero mi misión ante el pasado, parece ser la de votar en contra» (Mariátegui 1977 [1928], p. 229). 
los pintores peruanos románticos, cuyas obras remedaron cada detalle de la versión de los cuadros que copiaban (Salazar 1955d). Solo algunos pintores como Pancho Fierro superan «una primera capa de la represión y llevan a cabo así el primordial acercamiento a nuestra verdad» (Salazar 1955c). Otro esfuerzo lo llevó a cabo el Indigenismo, pues abrió «la compuerta de la censura» y permitió el ingreso del hombre, la tierra, la naturaleza y la vida de los peruanos como elementos dignos de ser incluidos en una pintura sin rubor ni desdén (Salazar 1955e). Sin embargo, estos ejemplos son muy escasos. La mayoría de las veces los artistas olvidan que su compromiso tiene al final un carácter moral:

[...] no hay arte sin función ética, entendida esta como compromiso para una sociedad y un tiempo, y de que, asimismo, es fundamental en el artista completo un anhelo vital de comunicarse con los demás por medio de sus creaciones. (Salazar Bondy 1955c)

Al involucrarse con la sociedad, el arte cobra una dimensión ética, pues se relaciona con los demás. Si no se alcanzara esta relación, su propósito y anhelo vital se echarían a perder y perdería su capacidad para oponerse a los elementos anquilosados y establecidos de la sociedad.

Otro campo que no puede olvidarse en esta relación entre Salazar y el realismo se encuentra en el teatro y la literatura que escribió. Luego de publicar una poesía hermética y expresionista y algunas comedias y juguetes que se inspiraban en el teatro del absurdo, Salazar escribe piezas como No hay isla feliz (1954) y Algo que quiere morir (1956), que se inspiran en la vida de personajes que padecen los bruscos cambios económicos y sociales del país en esos años. Este realismo también se revela en libros de cuentos como Náufragos y sobrevivientes (1954e) ${ }^{3}$ y Pobre gente de París (1958g), que describen y profundizan en los nuevos espacios y problemáticas urbanas.

No obstante, tal vez el aspecto más importante en este regreso a las ideas de Mariátegui se encuentra en el lugar que poco a poco le empieza a dar al significado de la tradición en sus columnas. Desde sus reflexiones sobre la ciudad, sobre la literatura y sobre las políticas de las autoridades relacionadas con la ciudad, Salazar estará cada vez más interesado por las diferentes maneras de relacionarse con el pasado, así como por el trasfondo ideológico que hay detrás del tradicionalismo.

\section{Tradición y tradicionalismo en la ciudad}

Uno de los temas que más le preocupan a Salazar Bondy es el peligro en que se encuentran los diferentes edificios, casonas y otros monumentos del Centro de Lima,

3 En el cuento «Volver al pasado», incluido en este libro, una mujer descubre que el hogar de su infancia se ha convertido en un prostíbulo; en el cuento «Pájaros», el lector asiste al monólogo interior de una prostituta. 
deteriorados por el descuido de sus propietarios y la indiferencia de las autoridades. Sin embargo, el escritor sabe que la amenaza que pende sobre estos inmuebles no se debe solamente al abandono en que se encuentran sino también la fiebre progresista, que no tiene reparos en derrumbar las casas viejas o cuadras enteras para luego levantar modernos edificios o construir largas avenidas. Así, lo que se debe buscar en la ciudad es el equilibrio entre lo antiguo y lo nuevo, entre la herencia cultural y las novedades que nos trae la historia: «la misión de una generación no es, por más revolucionaria que sea, cortar con todo lo que precede, sino encontrar el lazo sutil y profundo que la vincula con lo que ha sido y con lo que será» (1956a). En vez de adoptar una actitud iconoclasta ante el pasado, lo que se necesita hacer es intentar preservar el antiguo esplendor de la ciudad:

Sin ser pasatista o futurista, se puede conciliar - como se concilia en otras partes del orbe- el afán de mejorar la vida presente con el deber de mantener dignamente aquello que habla de cosas a las que los siglos dan el toque ilustre que llamamos tradición. A un país se le conoce y aprecia no solo por las obras que revelan su celo por alcanzar un alto grado de civilización para el pueblo, sino también por la manera cómo se hace hijo de sí mismo en la devoción por el patrimonio que conforma su personalidad eterna. (1956a)

La conciliación entre el pasado y el futuro - y no la imposición de una visión sobre otra- permitirá salvaguardar los bienes heredados de la historia. La preservación de la tradición es la manera en que un pueblo se hace "hijo de sí mismo" y poco a poco forma su "personalidad eterna".

Una opinión parecida a esta se encuentra en el artículo "Balcones apolillados y tradición”, en el que Salazar sostiene que no tiene propósito defender los inmuebles vetustos cuando estos solo envejecen y no sirven para entablar un contacto con el pasado. Por tanto, lo que se debe hacer es "seleccionar qué detalles o qué conjuntos de la ciudad son una lección de armonía, de cultura, de conformidad entre el hombre y el medio" porque estos son los elementos que permiten "definir nuestro ser", por más tormentoso y contradictorio que sea este (1958f). Así, lo que se busca es encontrar un equilibrio entre la tradición y el presente: "La etimología de la palabra tradición alude a esa especie de posta que llevan a cabo unas generaciones con respecto a las otras, a las que preceden" (1958f). Tal como sucede en las ciudades de Europa, los limeños deben tener una tradición viva, no un pasado muerto.

Sin embargo, el debate sobre la tradición no solo toca a los pasatistas o a los futuristas sino también a quienes desean recuperar el pasado por medio de la imitación. Un tema que preocupará mucho a Salazar es la difusión del "neocolonial”, el estilo arquitectónico que pretende parecerse a las antiguas casonas de la Colonia pero que termina por no ser más que un añadido postizo:

Todo lo que pretende ser "neo-colonial" (horrible palabra que mistura la novedad con el pasatismo falsificado) es tan atentado como todo lo que es culto rastacuero a la modernidad a ultranza. (Salazar 1958g) 
Para el escritor, el neocolonial es tan inapropiado como ese afán por construir edificios exageradamente modernos en la ciudad porque ambas opciones terminan por ser falsos. Es un estilo que se viste de pasado pero que en el fondo no permite la comunicación con el pasado, como sí lo haría una construcción antigua debidamente preservada. Este es el caso de los portales de Escribanos y Botoneros, construidos en los años cuarenta, o del Banco Internacional, que se encuentra frente a la Iglesia de La Merced. A este cuadro del Centro de Lima se suman las frígidas líneas del supermercado Monterrey, que colaboran con esa extraña mezcla de estilos que convierten la ciudad en una «ácida ensalada».

Estos últimos artículos demuestran que Salazar no piensa en la tradición como un elemento extraño y perteneciente al pasado sino como un factor que contribuye al devenir histórico del presente. La condición abierta permite integrar a la tradición los cambios que se producen en el tiempo y transmitir y fortalecer un sentido de identidad en quienes viven hoy y vivirán en el mañana. No ocurre así con el tradicionalismo, que se acerca al pasado de una manera artificial.

Sin embargo, el tradicionalismo no se encuentra solamente en la arquitectura sino en el propio poder. En una serie de artículos que aparecen publicados en un lapso de pocas semanas, Salazar denuncia el modo en que la Municipalidad expulsa a los ambulantes de la ciudad con la ayuda de la policía con el pretexto de mantener y cuidar la imagen y el ornato de la ciudad pero, en realidad, con el fin de conservar la imagen idílica la ciudad colonial. Así, las autoridades utilizan sistemas parecidos a aquellos funcionarios zaristas que ocultaban a su monarca la realidad colocando fachadas de cartón para que no observe la suciedad de la ciudad o a aquellos países donde se encierra a los mendigos en la cárcel o el asilo para que los turistas no se lleven una mala idea de la situación (1960b). En estas dos situaciones —la de la canción criolla y la de los ambulantes en el centro de la ciudad- se descubre que el modo de preservar la tradición es equivocado y hasta nocivo. Por imponer una imagen ya no solo se crean efemérides ficticias, sino que hasta se justifica la desigualdad.

Esta alianza entre el poder y el tradicionalismo no solo se expresará mediante el uso de la fuerza sino a través de la misma literatura. En un artículo titulado "Lima y lo limeño", en el que se comenta la aparición de una colección de literatura limeña publicada por el Concejo Provincial de Lima, Salazar se pregunta si las obras que se incluirán en ella solo estarán dedicadas a la tapada, los balcones y las costumbres capitalinas o también contará con la de aquellos autores que no recurrieron a los lugares comunes para hablar de la ciudad. Desde hace mucho tiempo — señala el escritor- los escritores y los viajeros extranjeros han ensalzado o denigrado la ciudad, terminando por crear una literatura exterior y superficial que solo se ocupa por señalar las "particularidades de los hábitos sociales e individuales de los pobladores de nuestra capital, generalmente con una gracia festiva que la hace singular" (1959a). No obstante, este tipo de literatura limita las muchas otras maneras de 
entender y conocer la ciudad. En vez de hacer una antología solamente con escritores satíricos y costumbristas, Salazar sugiere incluir a poetas como José María Eguren, cuyos versos escapan a la regla del tipismo limeñista:

$¿$ No hay bastantes poemas de este artista que, aunque no nombren calles, lugares, costumbres, etc., son más cabalmente limeños que muchas coplas o crónicas con picarones y marineras? [...] ¿ ¿acaso no se han dado escritores como Xavier Abril, Martín Adán, Emilio Westphalen, Javier Sologuren, Julio Ramón Ribeyro, Enrique Congrains [...] en los que bulle algo que puede ser llamado limeñidad o limeñismo no pintoresco? (1959a)

Con estos nombres, Salazar propone una tradición nueva para una ciudad que solo se ha interesado por visibilizar una parte de la cultura y la historia de Lima. En vez de lo "limeño", que implica todo aquello relativo a la Colonia y el criollismo, Salazar propone la "limeñidad", con lo que se podría conocer la ciudad a partir de nuevas formas. A partir de los escritores que menciona, podemos deducir que se refiere a esa ciudad representada en los versos de los poetas simbolistas y vanguardistas y al realismo literario de los años cincuenta.

No obstante, estas imágenes no solo fortalecen la ideología colonialista, sino que también colaboran con hacer olvidar la importancia histórica de la capital peruana. En el artículo "Lima y su destino", el escritor señala que este pasado decorado con salones, danzas y duelos amorosos ha hecho que se dejen de recordar aquellos momentos importantes de la historia de Lima que tanto influenciaron el destino de la nación (Salazar Bondy 1961a). La memoria de la capital ha sido sintetizada en la imagen de la Perricholi y otros personajes similares, sin tomar en cuenta a aquellos gobernantes que tuvieron que enfrentar a los enemigos y a aquellas personalidades cuyas palabras decisivas influenciaron en el destino nacional. Por otro lado, Salazar también deja entrever que este pasado inventado termina por ocultar los hechos del presente, pues no describe el proceso de la migración. En vez de mostrar la realidad de la capital - un lugar donde las culturas criolla y andina se enfrentan- se prefiere poner la mirada en una ficción.

Con todo, Salazar siempre cree que es posible recuperar el ideal social que se le ha encomendado a la capital:

Una ciudad es siempre una utopía, un proyecto de dicha común, de coexistencia humana y paz social. Lima no escapa a esa norma y no podremos estar conformes, aunque la embellezcan edificios gigantescos y pulule en ella una muchedumbre ya innumerable, si todos los días sus hombres - por lo menos sus hombres conscientes- no luchan porque el arquetipo que está en el origen de la agrupación civil se cumpla en cierta medida. (Salazar Bondy 1961a)

Según el escritor, la capital no debe dejar de buscar ese ideal social —la utopía- que toda ciudad tiene de por sí. Más allá de lo sugestivo que puede parecer el pasado con su imaginario colonial o el futuro con sus prometedores edificios, se 
tiene que alcanzar ese proyecto de unión y comunidad que merece toda sociedad humana. También hay que destacar que la búsqueda de esta utopía es el resultado de una disconformidad con la ciudad. Tal como lo hiciera Mariátegui contra el tradicionalismo literario, Salazar lo hace lo propio contra el tradicionalismo en la ciudad.

A pesar de que no haya muchos artículos en los que se le mencione, se puede decir que el concepto de utopía se encuentra casi siempre presente en el pensamiento de Salazar. Sus comentarios sobre los espacios públicos, el urbanismo, las relaciones sociales o el poder político siempre apuntan a buscar una comunidad más democrática y mejor conformada. ${ }^{4}$ No obstante, cabe destacar que esta aspiración no solo se origina en un ideal moral sino también cultural. Tal como dice en un artículo titulado "La ciudad que semeja al país", el escritor subraya que el limeño contemporáneo debe aceptar que el mambo de Machaguay, el canto de Ima Súmac, la literatura de José María Arguedas o el folclor campesino que se presenta en las carpas son ya parte de la ciudad. Así, Lima debe ser consciente del complejo proceso que se está produciendo dentro de ella:

[A]sí como [el provinciano] recibe el impacto de la metrópoli, así como cambia sus maneras y sus características, adopta, en cambio, otras cosmopolitas o citadinas, entrega, por medio de una sólida permuta, ciertos elementos propios y los incorpora a la personalidad de la urbe, la cual en seguida los adquiere y particulariza. En su última visita a nuestra capital, el famoso antropólogo Paul Rivet afirmaba que veía con agrado y satisfacción que Lima se estuviera convirtiendo en una población india. Y esto es cierto. La provincia ha traído aquí esta peruanísima contribución racial y ella se ha tornado limeña (Salazar Bondy 1956c)

Salazar observa la ciudad como un escenario en el que se está produciendo un fenómeno social y cultural profundo. Literalmente, la ciudad ahora sí está pareciéndose al país porque está conformada por una "población india" que contribuye con sus propias tradiciones y conocimientos. Además, no es solo el perfil del limeño el que sufre cambios sino el del propio migrante, quien poco a poco las costumbres y particularidades de la ciudad.

Para Salazar, la tradición es el mejor medio por el cual el ciudadano limeño puede preservar su pasado, involucrarse con la historia de su ciudad y fortalecer su identidad cultural. De nada sirve conservar un edificio antiguo si será abandonado y terminará por deteriorarse, como tampoco servirá de mucho diseñar edificios que imiten las antiguas casonas virreinales porque no son las huellas verdaderas de la historia. Lo que se necesita es mantener «una especie de secuencia histórica que hace del presente una prolongación del ayer, una unidad del tiempo en el espacio, del tiempo en el hombre» (Salazar 1958c). Sin embargo, Salazar también descubre la necesidad de diferenciar la tradición del tradicionalismo. En consonancia con la

4 Susti sostiene que la utopía de la que habla Salazar aspira a un "ideal-ciudad", en el sentido de buscar un ideal de ciudad universal con el que se identifican todos los individuos (Susti 2016, p. 5). 
crítica de Mariátegui, el escritor encuentra que el afán de las autoridades por preservar la imagen colonial y criolla de la capital - sea por restringir el ingreso de los ambulantes migrantes al centro o por la publicación de una antología literaria que recuerda la Lima de antaño- limita significativamente la relación de los limeños con el pasado. En vez de conocer la profundidad histórica de la capital, como sí lo permite la tradición, este tradicionalismo presenta una imagen festiva y superficial del pasado, reduciendo la cultura de la capital a unos cuantos tópicos y ciertos personajes pintorescos. Finalmente, se puede decir que Salazar plantea la búsqueda una utopía que permita la superación de la desigualdad social y la integración de la diversidad cultural de la ciudad.

\section{Del pensamiento crítico a la acción política}

Otro factor importante en la evolución del pensamiento crítico de Salazar se encuentra en su acercamiento a la política. En el año 1955, Salazar se adhirió al Movimiento Social Progresista, partido político recientemente fundado por Alberto Ruiz Eldredge, Efraín Ruiz Caro y su hermano, el filósofo Augusto Salazar Bondy, convirtiéndose muy pronto en un activo participante y además en un frecuente colaborador de Libertad, el órgano de esta nueva agrupación. Tanto en este semanario como en los distintos diarios en los que escribió durante esta etapa, Salazar expone su opinión sobre las tensiones sociales, la política del momento y las decisiones de las autoridades ante los problemas del país y la ciudad.

Una de las ideas que aparece con frecuencia en sus artículos es su desconfianza ante las ideologías. Para Salazar, la clase política manipula a la ciudadanía con ideologías que sirven para crear corrientes de opinión a favor o en contra de aquello que les conviene. Cuando lo creen propicio, empiezan a difundir la idea de que «sin estaño no hay país» o que «sin azúcar no hay posibilidad de riqueza», pero solamente para que las compañías extranjeras puedan aprovechar los recursos nacionales y dejar de lado a las empresas del país (Salazar Bondy 1960c). Estas ideologías también sirven incluso para censurar las propias ideas, dice el escritor. Bajo la figura del nacionalismo, los políticos reprimen todas aquellas «ideas foráneas» que proponen cambios en las formas de pensar, olvidándose de que muchas de las ideas que hoy se consideran valiosas provinieron de otros países y otras épocas. Simón Bolívar y José de San Martín se inspiraron en el liberalismo norteamericano de Benjamín Franklin y Tomás Jefferson, mientras que los pacifistas del siglo XX tomaron las ideas de Gandhi y Henry Thoreau. Para Salazar, la sociedad contemporánea debe aspirar a la universalidad y no a las ideologías locales que solo buscan despertar el ánimo de los chauvinistas para beneficiar sus propios intereses (Salazar Bondy (1962c).

El rechazo de Salazar a las ideologías está estrechamente relacionado con el escepticismo que surgió en torno a ellas luego de los extremos a los que llegó el fascismo y el estalinismo durante la Segunda Guerra Mundial. En gran parte del pensamiento occidental de mediados del siglo XX, la ideología empezó a ser vista 
como un tipo de pensamiento «deformado» o «distorsionado» que se instituía bajo la presión de emociones como el odio, el deseo, la ansiedad o el temor para socavar las instituciones establecidas o como un elemento doctrinario y totalitario que aspiraba a la dominación universal. Libros como El fin de la ideología (1960), de Daniel Bell, o El opio de los intelectuales (1957), de Raymond Aron, describen la ideología como un pensamiento que prioriza ciertos aspectos de la realidad, pero oculta o deforma otros. Salazar también se muestra temeroso de que las ideologías se hagan dueñas de la vida política de los países, y es por eso que postula una sociedad en la que prevalezca el derecho de la libertad (y, con ello, la libertad de elección y opinión) y no la adhesión radical a uno u otro pensamiento:

Para el verdadero demócrata, para el demócrata humanista, que piensa en una libertad que no conduce al abuso, liberalismo y marxismo son siempre imperfectos. $\mathrm{Ni}$ que el estado se convierta en un policía que solo reprime los escándalos y las riñas, ni que el estado se torne en una maquinaria que todo lo absorbe y tritura, son los extremos que quien ama de veras la democracia y cree en su fuerza rechaza con igual energía. Un demócrata humanista pone en primer término al hombre —ni ángel ni demonio - y lo defiende de ser reducido a nada por las oligarquías egoístas o por el estatismo egoísta. (Salazar Bondy 1959c)

Bajo el modelo de una «democracia humanista», Salazar propone una comunidad en que el hombre se encuentre delante de las ideas y no las ideas delante del hombre, ya que los sistemas de pensamiento nunca carecen de defectos y suelen perder de vista valores verdaderamente democráticos como el de la libertad.

Las inconsistencias internas de las ideologías también se revelan fácilmente en el comportamiento de los partidos políticos peruanos. La intención de Acción Popular por nacionalizar el petróleo y enfrentarse a los Estados Unidos es solo un gesto, pues en el fondo nadie se atreverá a agravar al «amo yanqui»; el Apra tampoco convence cuando eslóganes como «educación gratuita», «vivienda popular» o «reforma agraria», pues ahora se ha convertido en un partido liberal y «libreempresista» (1962b). Para Salazar, la única ideología imperante en el país es el liberalismo, pues casi todos los grupos políticos terminan por favorecer el crecimiento desmedido del capital y olvidarse del bienestar social. Los liberales no se interesan por mejorar la vivienda o la salud pública sino establecer una cultura del presentismo que ignora la pobreza y la miseria (1960b). Su escasa preocupación por la planificación refleja, además, su rechazo a cualquier tipo de intervención de un estado regulador (1959b) que se preocupe por el crecimiento económico del país: «Que la carne suba de precio, que la gasolina aumente en un cien por ciento, que el pan se reduzca de tamaño, que la vida encarezca y los salarios queden congelados, etc., no es otra cosa que la matanza libre» (1959d). Este principio del «libre comercio» también se ha extendido a la educación y a la política cultural del país, ya que la enseñanza de calidad se ha reservado solamente a las castas y la oferta cultural se ha reducido al consumo del radioteatro, la prensa amarilla, el libro rosa, la televisión u otros ejemplos de la cultura de masas que contribuyen a oscurecer la mente y matar 
la imaginación. El liberalismo es un tipo de pensamiento que alienta la conducta cada vez más egoísta de los hombres (1962b).

La realidad política puede parecer muy complicada y con muchos problemas aún por resolver, pero para Salazar es una ocasión para reconocer los errores cometidos y buscar una posible solución. En vez de caer en el pesimismo, se debe intentar buscar una salida ante las dificultades que se presentan día a día, pues no hay que olvidar "que el tiempo prometido es infinito" y que en el cuerpo mismo de la colectividad "siempre se elaboran las defensas vitales que lo renovarán cuando la hora sea dada" (Salazar Bondy 1958c). Palabras como estas recuerdan esos artículos dedicados a la ciudad en los que también expresa su confianza por alcanzar esa sociedad ideal. No obstante, no tardará el momento en que el propio Salazar dejará de lado expresiones como estas y empezará a revelarse en él un tono menos esperanzador. Al parecer, ya no bastará con hacer recomendaciones y proclamar la necesidad de una mirada positiva sobre el futuro. Lo mismo ocurrirá con su opinión sobre las ideologías, pues poco a poco dejará de apostar por esa democracia libre de extremismos y de cierto equilibrio ideológico (esa democracia del "demócrata humanista") y optará por un abierto apoyo al socialismo.

Este cambio de perspectiva tiene estrecha relación con algunas experiencias de esos años. En 1959, Salazar renuncia al diario La Prensa cuando le prohíben publicar una serie de artículos en los que iba a exponer el pensamiento económico y social de Louis-Joseph Lebret. Este padre católico era el ejemplo sobre cómo se podía combatir la pobreza, enfrentar el liberalismo imperante en el país y el continente y, sobre todo, mantener el ideal de una sociedad integrada y compasiva con el más débil. Otro acontecimiento importante será su visita a la isla de Cuba en el año 1962, lo que lo acerca a los círculos de intelectuales y escritores de la izquierda latinoamericana y le permite conocer un país socialista. Frutos de este viaje son el libelo Cuba, nuestra revolución, donde expone los beneficios del socialismo (1962a), y el artículo «Andes and Sierra Maestra» [Los Andes y la Sierra Maestra»], ${ }^{*}$ en el que expresa su deseo de que en el Perú surja un frente revolucionario que, como en Cuba, pueda renovar las instituciones gubernamentales, acabar con la repartición desigual de la tierra y combatir la pobreza (1962a). Para el escritor, todas las condiciones sociales del país indican la necesidad de un cambio, pero también le preocupan las abismales diferencias económicas entre sus ciudadanos y la lejanía que existe entre la masa popular y el poder político. Esta situación, para la que también colabora la policía con sus medidas represivas, no permite que en el país se forme una clara conciencia popular ni se consolide una voluntad de poder que pueda consolidar el cambio. ${ }^{6}$

5 Artículo publicado en la revista marxista norteamericana Monthly Review.

6 El artículo de Salazar ejemplifica esta situación con el enfrentamiento entre la comunidad pasqueña de Yerús-Yacán y una compañía minera, que se disputan el uso de las tierras. Como es de esperarse, el gobierno ha acusado a los campesinos de realizar ataques armados y la empresa tiene 
Los artículos sobre política - y sobre todo aquellos que publica en el semanario Libertad - cada vez evidenciarán un apoyo más abierto al socialismo:

Solo la izquierda - y en ella principalmente, el socialprogresismo- enuncia objetivos básicos que emanan de la doctrina, que no se explican sino por la doctrina, que constituyen la única realización de la doctrina. Esta estricta correlación entre lo que se piensa y lo que se dice se llama, además, revolución. (Salazar Bondy 1962b)

Ante la falta de credibilidad de los partidos de derecha y el Apra, que manipulan la opinión pública y no cumplen lo que prometen, solo la izquierda será quien cumplirá su palabra. Empresarios, latifundistas y burócratas de alto nivel consideran que los partidos políticos representan el «orden» y el «bien», pero en realidad son los que primero colaboran con las clases más poderosas. Son estas agrupaciones, apoyadas por los liberales, quienes difunden ideas como «el cholo huele mal», «el obrero es bruto» o «quieren los izquierdistas el caos», además de difundir los privilegios de raza, de linaje, de ventaja económica o de dominio político. Según Salazar, el problema de la gran difusión que tienen estos mensajes es que al final terminan por convertirse en ideas fijas o, incluso, en derechos (Salazar Bondy 1961b).

La necesidad por participar del debate político responde a una convicción ideológica muy clara pero también se origina en un factor generacional. Como todos aquellos escritores que vivieron su juventud durante los años cuarenta, Salazar fue testigo del rápido fin del gobierno de José Luis Bustamante y Rivero (1945-1948) a manos del general Manuel Odría, que actuó como el caudillo de la oligarquía. Así, no es extraño que el retorno a la democracia en el año 1956 haya significado la oportunidad para poder abrazar nuevamente aquellos los ideales que había defendido cuando joven:

Generación angustiada la nuestra, su sueño ha sido vario y complejo, y a cada paso, en la sordidez de la dictadura y en el trance trémolo de la constitucionalidad, hemos padecido, y padecemos, la prueba de querer vivir de acuerdo a nuestros principios, contra las circunstancias externas que amenazan nuestras convicciones y las instituciones que las encarnan. (Salazar Bondy 1958d)

\footnotetext{
a la justicia de su parte. Sin embargo, también es verdad que la dificultad para llegar a una pronta solución se debe a la falta de organización de los pobladores y la falta de estrategia y liderazgo de los partidos de izquierda, que no permiten la formación de una conciencia política sólida. Hacia el final de su argumentación, Salazar advierte que este problema también encuentra en un espectro más amplio, ya que también hay muy poco en común entre el estudiante inconformista que se ha formado en las universidades de las grandes ciudades y la protesta de los campesinos. Si bien ambos tienen objetivos parecidos, los separa el idioma y el pasado, ya que la historia gloriosa del primero cuenta la historia de opresión del otro. «El concepto de integración entre los dos grupos - indio y blanco - tiene que concebirse como una búsqueda dinámica del segundo por el primero, y no de forma inversa». (Salazar Bondy 1962a)
} 
Ante la frágil estabilidad política del país, Salazar considera que la obligación de su generación es la de luchar por el mantenimiento del estado de derecho. Es un imperativo "vivir de acuerdo a nuestros principios", pues es solo de esta manera en que se podrán superar los peligros del poder mal manejado.

En el año 1962, Salazar postula como candidato a una diputación por el departamento de Lima y hace campaña por el Movimiento Social Progresista en las plazas Huancayo, Iquitos, Piura e Ica, aunque ni él ni ningún otro miembro del partido alcanzarán el porcentaje suficiente como para ocupar un escaño. No obstante, estas actividades no detendrán su pasión literaria y periodística. En 1963 empieza a trabajar como subdirector editorial de la recién fundada revista Oiga y luego forma parte del comité editorial de la revista Proceso — en una clara referencia a José Carlos Mariátegui- junto con Abelardo Oquendo, Mario Vargas Llosa, José Miguel Oviedo y Luis Loayza. Con el propósito de revalorar la crítica literaria peruana, estos jóvenes escritores buscarán recuperar el papel del intelectual en la sociedad peruana: «Nos corresponde reflejar nuestra propia búsqueda de certidumbre, nuestro inconformismo ante la realidad peruana, nuestra actitud de examen frente al pasado», dice el editorial del primer número publicado en el verano de 1964.

El interés de Salazar por la política responde a su preocupación por mejorar no solo la dinámica social y cultural de la ciudad y el país sino también el modo en que el poder político se organizaba y respondía a las necesidades más urgentes. En vez de ser solo un observador, el escritor pasa a convertirse - aunque sin éxito- en un actor más de la escena política de su tiempo. En este tránsito, su tarea será la de acusar la falsedad de las "ideologías" — aquellos mensajes creados a propósito para engañar- $y$ revelar las inconsistencias de aquellos partidos políticos que no cumplen con lo que prometen. Ante ello, su propia opción política consiste en militar en una agrupación política que - al menos en teoría, pues nunca llegó al podersí pretende mantener la coherencia entre lo que dice y lo que realiza. También es importante destacar las críticas de Salazar al capitalismo, pues sus comentarios no solo van dirigidos a las propias leyes del libre mercado. Para él, el peligro se encuentra en que la mala calidad de los productos pronto alcanzará la educación y luego la cultura. Ante un poder que solo le interesa la ganancia, la enseñanza solo se reservará para aquellos que pueden pagarla y la cultura se convertirá en un mero producto de consumo.

\section{A las puertas de Lima la horrible}

Los artículos periodísticos publicados entre el retorno de Argentina al Perú en el año de 1951 y la publicación de Lima la horrible en 1964 permiten conocer las diferentes facetas de Salazar en torno al tradicionalismo limeño. Los viajes, las lecturas de Mariátegui y las experiencias relacionadas con la política, llevaron al autor a plasmar una visión crítica amplia y abierta sobre la tradición cultural de una ciudad, $\mathrm{y}$ estos textos son la primera evidencia. 
Este largo periodo de reflexión crítica se puede resumir en tres facetas claramente reconocibles. La primera es aquella en la que Salazar se encuentra estrechamente familiarizado con el discurso tradicionalista limeño de su tiempo. Muchos de sus artículos - e incluso sus poemas - muestran la cercanía y el conocimiento que tiene de la historia, los personajes y los lugares relacionados con la Colonia, lo que revela lo importante que era para él la memoria del pasado. Sin llegar a ser un limeñista que busca volver al pasado — su tendencia se aproxima más a la literatura criollista de Diez Canseco y Beingolea-, su preocupación está enfocada en el modo en que el ciudadano contemporáneo puede preservar y mantener el contacto con la historia. A todo esto, se suma también su afición por las Tradiciones Peruanas y por la figura de Ricardo Palma. Aquellos artículos publicados en 1953 y 1958 en los que reclama la necesidad de recordar el legado literario del escritor, son una manera de reconocer la capacidad de la literatura para poder recuperar y actualizar el pasado en el presente. Así, la obra de Palma se convierte en un factor imprescindible para los limeños que quieran conocer y revivir los tiempos de la Colonia.

Una segunda faceta se produce cuando Salazar incorpora la lectura que realiza de José Carlos Mariátegui a su propio comentario crítico. Así como el Amauta votó en contra de la crítica de su tiempo, al escritor también le parecerá necesario enfrentar la permisividad de los críticos literarios de su generación, acostumbrados a ser indulgentes con los escritores y muy sensible ante las observaciones aquellos que sí atrevían a decir qué es lo que les gustaba o les parecía malo. Es importante que la crítica pueda hacer un juicio objetivo y libre y no ceder ante aquellas influencias que doblegan su propósito principal.

Este acercamiento a la reflexión de Mariátegui también se revelará en otros aspectos. Uno de ellos es su interés por formar una literatura que se encuentre comprometida con los problemas sociales de su tiempo. Para la creación de una literatura nacional - como también se postula en los 7 ensayos-, el escritor debe escribir desde su propio presente histórico y no temas que, como los de la Colonia, hablan de contextos tan lejanos a los de la Lima contemporánea. El otro es su afán por mantener una relación viva y creativa con el pasado histórico de la ciudad. En vez de defender el pasado a ultranza y mantener intactas las casonas y los edificios de la Colonia, Salazar considera que estos lugares formar parte de la dinámica de la capital porque si no se echarán a perder por completo y finalmente a olvidar. Al igual que Mariátegui, el escritor piensa que para poder conservar la historia hay que integrarla al presente — tal como se hace en muchos países de Europa- pues es así como se preserva la verdadera tradición. Lo que se debe evitar, por tanto, no solo es el conservadurismo pasatista sino también esa pretensión por rescatar el pasado por medio de su imitación. El estilo "neocolonial" - que copia los estilos arquitectónicos de la Colonia- es en el fondo una forma falsa de relacionarse con la historia porque solo remedo y no permite establecer una auténtica relación con el pasado. 
Salazar también descubrirá que esta mirada pasatista y tradicionalista sobre el pasado no solo se encuentra en la arquitectura sino en el mismo discurso oficial. Los círculos intelectuales y las instituciones públicas - como la Municipalidad de Lima, por ejemplo - insisten en restringir la imagen de Lima a todo lo colonial y lo criollo, limitando las otras interpretaciones que hay sobre la ciudad (por ejemplo, como la propuesta por poetas como José María Eguren y Martín Adán). Otra consecuencia directa de la difusión de esta imagen tradicionalista se encuentra en que ella colabora con ocultar la realidad presente. En vez de reducir la capital a los cuentos de la Colonia, las autoridades - y con ellas los intelectuales y los artistasdeberían fijar su atención en procesos como el de la migración o los cambios culturales que esta está produciendo en la capital. Solo mediante una imagen abierta, libre e inclusiva de la capital se podrá alcanzar la utopía social de la que habla en el artículo "Lima y su destino".

La tercera faceta en el pensamiento de Salazar es el que comienza con su participación en el debate político de su tiempo. Atraído por la propuesta del Movimiento Social Progresista, su primera postura será la de señalar a todos aquellos grupos políticos difunden ideas - “ideologías", dice Salazar- por propia conveniencia o para poder alcanzar sus fines, engañando a la opinión pública y aplazando los verdaderos problemas de la sociedad. Con el tiempo, sin embargo, su posición será cada vez más radical y el blanco de sus críticas será la economía liberal. Para Salazar, una sociedad capitalista que no tenga supervisión del estado terminará por crear un país que crecerá según los intereses de los más poderosos y debilitando a los más marginados. A su parecer, su generación debe comprometerse con la realidad del momento y transmitir su inconformismo ante la política de su tiempo.

El recuento que aquí se ha hecho permite conocer el interés que Salazar tuvo por el tema de la Colonia desde los primeros años en que empezó a ejercer el periodismo y el modo en que poco a poco se fue alejando y haciéndose más crítico de ella. Sin embargo, este cambio no implicó un rechazo de los temas relacionados con esta parte de la historia peruana - tan presentes todavía en su época- sino una crítica al modo en que estos eran presentados. En pocas palabras, su crítica estuvo dirigida al tradicionalismo limeñista que reducía la tradición cultural peruana a lo limeño y dejaba de lado las otras tradiciones culturales del país, la nueva situación social de la capital peruana (especialmente, la presencia de los migrantes) y las diferentes interpretaciones sobre la ciudad que podían provenir de las artes (en la literatura, la obra de Martín Adán y José María Eguren, por ejemplo). A diferencia de esta mirada pasatista y conservadora que él identifica en la literatura tradicionalista, en la arquitectura neocolonial y en las decisiones políticas de instituciones como la Municipalidad de Lima, su propuesta consiste en alentar una interpretación realista, crítica y comprometida con la realidad social. Salazar retoma el "voto en contra” alguna vez esgrimido por José Carlos Mariátegui contra la tradición colonial para adecuarlo a su tiempo, el Perú de mediados de los años cincuenta, y volver a decir que es necesario tener una perspectiva más abierta sobre la tradición. 
En este sentido, es importante recalcar que esta crítica al tradicionalismo limeñista no significa un desprecio por la tradición colonial. Él es el primero en insistir en que se deben preservar los monumentos históricos (siempre y cuando no signifique abandonarlos y condenarlos a la destrucción) y dentro de estos monumentos se encuentran las casonas, edificios y otros símbolos coloniales. Por otro lado, su crítica a la ciudad también es muy diferente a su admiración por la literatura de Ricardo Palma, cuya representación de la Colonia admira.

Los años en que Salazar se acerca al debate ideológico y a la vida política parecen alejarlo de los temas que había tocado durante la mayor parte de la década de los cincuenta. En realidad, todavía el escritor no encuentra la estrecha relación que existe entre la ideología burguesa y el tradicionalismo, como ocurrirá en Lima la horrible (1964). Sin embargo, estos artículos son ya una muestra sobre cómo descubre que gran parte de los problemas contemporáneos se deben a esa poca relación que existe entre el discurso y la realidad, tal como acusa en los partidos políticos de su tiempo.

\section{Referencias}

Calle, Karen. (2015). “José Carlos Mariátegui leído por Sebastián Salazar Bondy: el discurso crítico del ensayo y el compromiso intelectual", en Revista Virtual de Literatura El Hablador, No. 22, visitado el 14 de noviembre del año 2016 en http://www.elhablador.com/articulos22_calle.html

(2016). La crisis del imaginario sobre la ciudad y la construcción del sujeto crítico en Lima la horrible de Sebastián Salazar Bondy. Tesis para optar el título de Licenciada en Literatura, Universidad Nacional Mayor de San Marcos, Lima.

Contreras, Carlos y Marcos Cueto. (2004). Historia del Perú contemporáneo. Desde las luchas por la Independencia hasta el presente. Lima: Instituto de Estudios Peruanos. 3ra ed.

Cotler, Julio. (1978). Clases, Estado y nación en el Perú. Lima: Instituto de Estudios Peruanos.

Mariátegui, José Carlos. (1977) [1928]. 7 ensayos de interpretación de la realidad peruana. Lima: Biblioteca Amauta.

Ortega, Julio. (1986). C Cultura y modernización en la Lima del 900. Lima: Cedep.

Porras, Raúl. (1965) [1935]. Pequeña antología de Lima: el río, el puente y la alameda. Lima: Instituto Raúl Porras Barrenechea.

Revista Proceso. (1964). "Editorial”, No. 0.

Rodríguez, Celia. (2005). El discurso sobre arte de Sebastián Salazar Bondy. El tacto imperceptible. Tesis para optar el título profesional de Licenciada en Arte, Universidad Nacional Mayor de San Marcos, Lima. 
Sanders, Karen. (1997). Nación y tradición: cinco discursos en torno a la nación peruana, 1885-1930. Lima: FCE.

Salazar Bondy, Sebastián. (2016). La ciudad como utopía. Artículos periodísticos sobre Lima 1953-1963. Sebastián Salazar Bondy. Fondo Editorial de la Universidad de Lima.

- (2014a). La luz tras la memoria. Articulos periodísticos sobre literatura y cultura (19451965), tomo I. Lima: Lápix.

- (2003). Escritos politicos y morales (Perú: 1954-1965). Lima: UNMSM.

- (1964). Lima la horrible, México D.F.: Era.

- (1962a). Cuba, nuestra revolución, Lima: Ediciones de la Patria Libre.

- (1962b). «La verdad que ya viene». En Libertad, 2 de mayo, p. 12

- (1962c). «Ideologías: nacionalidad y universalidad». En Libertad, 30 de mayo

- (1961a). «Lima y su destino». En El Comercio, 18 de enero, p. 2.

- (1961b). «La derecha y el resentimiento». En Libertad, 23 de agosto de 1961, p. 5. [Salazar 2003: 157]

- (1960a), «El deber del escritor en un país subdesarrollado». En El Dominical, Suplemento del diario El Comercio, 28 de febrero.

- (1960b). «Fórmulas contra el destino». En El Comercio, 7 de abril, p. 2.

- (1960c). «Una ideología en estado salvaje». En El Comercio, 12 de setiembre, p. 2. [Salazar 2003: 151]

- (1959a). «Lima y lo Limeño en una antología». En La Prensa, 28 de enero, p. 14.

- (1959b). «Agitadores y agitados». En La Prensa, 3 de junio.

- (1959c). «El hombre no es egoísta». En La Prensa, 9 de junio, p. 2

— (1959d). «Matanza libre». En Libertad, 13 de agosto, p. 5

- (1958a). «Ricardo Palma, Lima y la gratitud». En La Prensa, 7 de febrero.

- (1958b). « ¿Una ciudad de rascacielos?». En La Prensa, 9 de julio.

- (1958c). «¿Está el Perú en crisis?». En La Prensa, 3 de setiembre.

- (1958d). «Una generación ante el conflicto». En La Prensa, 8 de setiembre, p. 8.

- (1958e). «117 manzanas y la arquitectura de Lima». En La Prensa, 29 de octubre, p. 14.

- (1958f). «Balcones apolillados y tradición”. En La Prensa, 18 de julio, p. 12.

- (1958g). Pobre gente de París. Lima: Populibros.

— (1956a). «Una alameda: pasado y futuro». En La Prensa, 27 de setiembre. 
- (1956b). «La ciudad que semeja al país». En La Prensa, 16 de febrero.

- (1955a). «La misión docente del escritor y el artista». En La Prensa, 24 de setiembre.

— (1955b).«El arte colonial entendido como represión». En La Prensa, 29 de setiembre.

- (1955c). «Los que intentan vencer el complejo». En La Prensa, 30 de setiembre.

- (1955d). «Hallazgo de la realidad perdida: siglo XX». En La Prensa, 1 de octubre.

- (1954a). «Un voto en contra de la literatura peruana». En Generación, No. 7, AbrilMayo.

- (1954b). «Sobre arte abstracto». En La Prensa, 30 de mayo.

- (1954c). «Los críticos del crítico». En El Comercio, 20 de setiembre.

- (1954e). Náufragos y sobrevivientes. Club del Libro Peruano: Lima.

- (1953a). “Fundación”. En La Prensa, Lima, 6 de enero, p. 6.

- (1953b). "Ricardo Palma”. En La Prensa, Lima, 6 de octubre.

- (1952). Rodil. Drama en tres actos, Lima: Tipografía Peruana S. A.

- (1950). "Plaza de armas". En La Prensa, Lima, 13 de agosto.

Susti, Alejandro. (2016). "Escribir sobre la ciudad: la crónica periodística en Sebastián Salazar Bondy". En La ciudad como utopía. Artículos periodisticos sobre Lima 1953-1963. Sebastián Salazar Bondy. Lima: Fondo Editorial de la Universidad de Lima.

— (2014a). "La crítica periodística de Sebastián Salazar Bondy". En Sebastián Salazar Bondy. La luz tras la memoria. Artículos periodísticos sobre literatura y cultura (1945-1965), t. I, Lima: Lápix.

Velázquez, Marcel. 2002. El revés del marfil. Nacionalidad, etnicidad, modernidad y género en la literatura peruana. Lima: Editorial Universitaria de la Universidad Nacional Federico Villarreal.

VV.AA. (2015). Coloquio Sebastián Salazar Bondy: Todo esto es mi país, organizado por el Programa de Estudios Generales de la Universidad de Lima y la Cátedra Vargas Llosa. 5, 6 y 7 de mayo en el Auditorio ZUM de la Universidad de Lima, Lima. Todas las conferencias en: http://bit.ly/2m1e7JF (revisado el 14/11/2017). 